\title{
A CASE REPORT OF PALATAL HAMARTOMA WITH BIFID TONGUE: RARE CONGENITAL ANOMALY
}

Somashekhar Samagandi1 ${ }^{1}$, Mohammed Shafiuddin², Shekappa C. Malagimani ${ }^{3}$, Rohith $\mathrm{M}^{4}$, Ayyappa S. A ${ }^{5}$

\section{HOW TO CITE THIS ARTICLE:}

Somashekhar Samagandi, Mohammed Shafiuddin, Shekappa C. Malagimani, Rohith M, Ayyappa S. A. "A Case Report of Palatal Hamartoma with Bifid Tongue: Rare Congenital Anomaly". Journal of Evolution of Medical and Dental Sciences 2014; Vol. 3, Issue 51, October 09; Page: 12019-12022, DOI: 10.14260/jemds/2014/3585

ABSTRACT: Here is a rare case of congenital anomaly, palatal hamartoma with bifid tongue in a 5 month old infant with non-oral-facial-digital syndrome. Informant, mother complain of difficulty in sucking breast milk and dribbling of milk during breast feeding and swelling in the palatal part of the oral cavity, mucous cyst in the floor of the mouth. The palatal swelling excised and the bifid tongue was repaired in layers surgically. Diagnosis of palatal hamartoma was based on the histopathological report. The review of literature, the description of the lesion, the diagnosis and the management of this finding are outlined.

KEYWORDS: Hard Palate, Bifid tongue, Hamartoma.

INTRODUCTION: Hamartoma, a benign tumour like malformation composed of a disordered mixture of mature tissue that normally occur in the affected part, but with a predominance of one particular tissue.(1) Tongue develops during $4^{\text {th }}$ week of gestation, in the floor of the primitive oral cavity. Two lateral lingual swellings and one median swelling Tuberculum impar from $1^{\text {st }}$ pharyngeal arch forms the anterior $2 / 3^{\text {rd }}$ of the body of the tongue.

The lateral lingual structures rapidly grow and cover the tuberculum impar to form the anterior $2 / 3^{\text {rd }}$ of the tongue. When this process is disturbed, the tip of the tongue is divided longitudinally for a certain distance giving rise to cleft tongue or bifid tongue. They may occur as an isolated entity or a part of clinical syndrome with oral-facial-digital abnormalities. $(2,3,4,5)$

CASE REPORT: A 5 month old female infant presented with swelling in the mouth, slowly growing in size since birth. History of difficulty in swallowing and dribbling of the milk during breast feeding was present. There is no significant antenatal history (mother non-diabetic). Baby was delivered at term normally.

On examination baby was malnourished.

Tongue was bifid in its anterior $2 / 3^{\text {rd }}$ completely. Mucous cyst present in the floor of the mouth at frenulum measuring about $3 \times 3 \mathrm{cms}$. Big soft swelling over the hard palate measuring about $5 \times 5 \mathrm{cms}$ protruding through the mouth exteriorly. Extra oral examination revealed no congenital facial defects. Systemic examination reveals no congenital digital and other anomalies (Fig 1). 


\section{CASE REPORT}

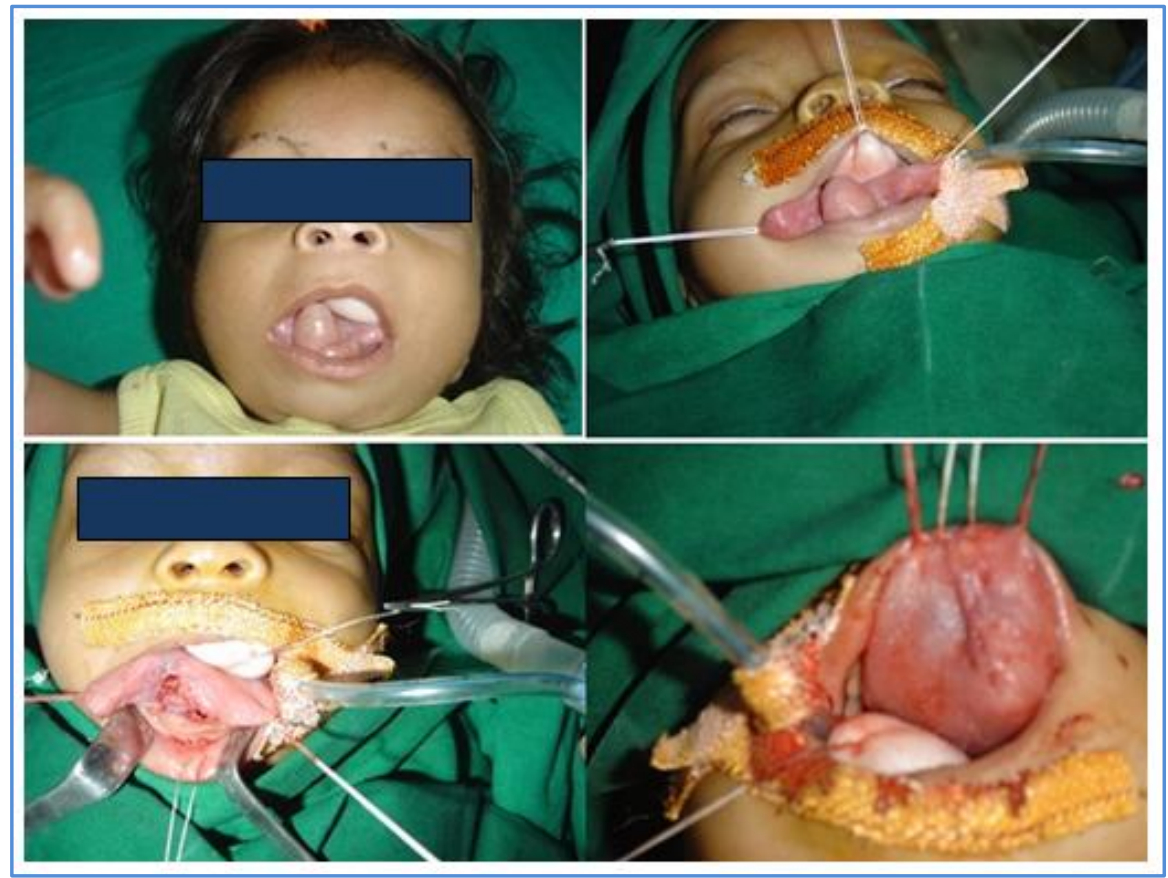

Fig. 1: various images of bifid tongue

Surgical correction of the defect taken under general anesthesia. First mucous cyst was excised. Tongue was reconstructed by refreshing the defects and sutured in layers. The palatal swelling is excised. Post-surgical healing was uneventful (Fig.2).

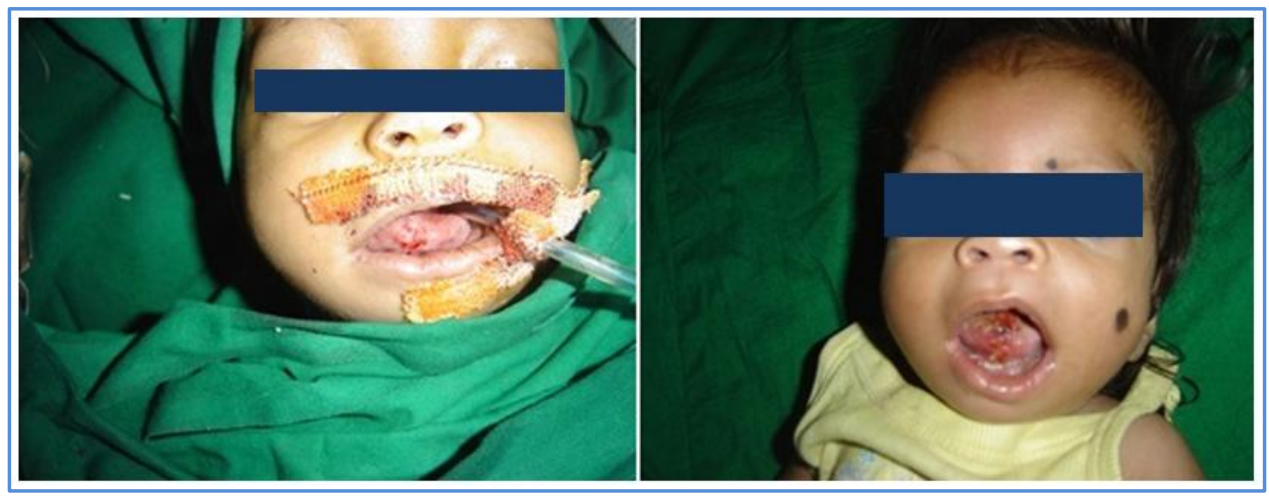

Fig. 2: Post-operative images

DISCUSSION: It is reported in the literature that median tongue clefts only to be associated with orofacial digital syndromes type I, II, IV and VI.(2,4,5) These syndromes are all associated with mandibular clefts, median lip, bilateral dislocation of knees, elbows, ankles, pulmonary hypoplasia and dysmorphic facial features including prominent forehead, depressed nasal bridge and widely spaced eyes were suggestive of Larsen-like syndrome type $1,(6,7,8)$ optic G BBB syndrome, oral facial 
digital syndrome type 1, Klippel-Feil anomaly. Bifid tongue has also been reported as a rare feature associated with infants of diabetic mother. $(2,3,9)$

Congenital lipomas of the fornix of the vestibule and of the tongue were reported in a 7 month old boy and 20 day old girl respectively. Congenital hairy polyps of the nasopharynx in association with cleft palate were diagnosed in two new born.(10) Oral hamartoma usually arises from the foramen cecum during embryonic development, which may explain why most LLH are in the midline of the tongue.(1)

The development of the tongue starts at the fourth week of intrauterine life in the floor of the primitive cavity from the first three or four branchial arches. Abnormal/ partial/ non-fusion of these arches may lead to congenital anomalies of tongue, including bifid tongue.(2) Our case was not associated with any syndrome or any other associated orofacial abnormalities or no history of post natal trauma, no genetic predisposition, no tongue piercing.

CONCLUSION: Bifid tongue can be described as cleft tongue/ diglossia, though many orofacial syndromes associated with it. Our case cannot be put in any well-defined syndrome and the palatal hamartoma with bifid tongue in a 5 month old infant is a rare case.

\section{REFERENCES:}

1. Hsing-Liang Wang, Feng-Yu Chiang, Chih-Feng Tai, Kun-Bow Tsai and Ling-Feng Wang-Lingual leiomyomatous hamartoma with bifid tip and ankyloglossia in a patient without oral-facialdigital syndrome: a case report and literature review. World Journal of Surgical Oncology 201311: 230.

2. Surej Kumar L. K., Nikhil M. Kurien, Madhu P. Sivan- Isolated congenital bifid tongue: National Journal of Maxillofacial Surgery Jul-Dec 2010; 1(2):187-189.

3. Etty Daniel Spiegel, Moshe Ben Ami- Bifid tongue, A Rare Congenital Malformation, Is a Prenatal Clue for Secondary Cleft Palate. J Ultrasound Med 2012: 31. 505-509.

4. Umesh K. Kulkarni, Deepali U. Kulkarni-Bifid Tongue, a Case Report. National Journal of Clinical Anatomy, 2013; 2 (2) Pg. 97-98.

5. Vela Desai, Prerna Pratik, Rajeev Sharma- Non Syndromic Bifid Tongue, a Rare Case Report. J Adv Med Dent Scie 2014: 2 (1): 106-108.

6. S. Rao, S. S. Oak, M. Wagh and B. Kulkarni- Congenital Midline Palatomandibular Bony Fusion with a Mandibular Cleft and a Bifid Tongue. British Journal of Plastic Surgery (1997) 50. 139141.

7. Ercan Mihci, Sukran Tacoy, Gulay Ozbilim, Brunella Franco- Oral Facial Digital Syndrome Type 1, Indian Pediatrics 2007 Nov 17; 44,.

8. Diclehan Orhan, Sevim Balei, Ozgur Deren, Eda Gulen Utine, Ahmet Basaran, Gulsev KalePrenatally Diagnosed Lethal Type Larsen-like Syndrome associated with Bifid Tongue-Turkish Journal of Pediatrics 2008. 50: 395-399.

9. Rohan Rai, Ashwin R Rai, Rajalaximi Rai, Keshav Bhat, Prevalence of Bifid Tongue and Ankyloglossia in South Indian Population With an Emphasis on its Embryogenesis, Int. J. Morphol 30 (1), 182-184. 2012.

10. Md Akbar Hussain Bhuiyan, Md Ashraf ul Huq kazal, Shahanara Chowdary, Shafqat Havider Chowdary. A Case Report on Palatal Dermoid with Bifid Tongue JCMCTA 2009, 20 (1) 58-60. 


\section{CASE REPORT}

\section{AUTHORS:}

1. Somashekhar Samagandi

2. Mohammed Shafiuddin

3. Shekappa C. Malagimani

4. Rohith M.

5. Ayyappa S. A.

\section{PARTICULARS OF CONTRIBUTORS:}

1. Associate Professor, Department of Plastic Surgery, VIMS, Bellary.

2. Associate Professor, Department of Surgery, GIMS, Gulbarga.

3. Associate Professor, Department of Surgery, VIMS, Bellary.

4. Post Graduate student, Department of Surgery, VIMS, Bellary.
5. Senior Resident, Department of Anaesthesiology, VIMS, Bellary.

\section{NAME ADDRESS EMAIL ID OF THE CORRESPONDING AUTHOR:}

Dr. Shekappa C. M,

B/24, Staff Quarters, VIMS (OPD) Cantonment, Bellary.

Email: doc_shekar@yahoo.com

Date of Submission: 26/09/2014. Date of Peer Review: 27/09/2014. Date of Acceptance: 30/09/2014. Date of Publishing: 09/10/2014. 